Research Article

\title{
Multiobjective Optimization Method and Application of Tolerance Allocation for the Steam Turbine Based on Cooperative Game Theory
}

\author{
Li-li Li, ${ }^{1}$ Kun Chen ${ }^{D},{ }^{1}$ Jian-min Gao, ${ }^{1}$ Jun-kong Liu, ${ }^{1}$ Zhi-yong Gao, ${ }^{1}$ and Man-xian Wang ${ }^{2}$ \\ ${ }^{1}$ State Key Laboratory of Mechanical Manufacturing Systems Engineering, Xi'an Jiao Tong University, Xi'an 710049, China \\ ${ }^{2}$ AECC Xi'an Aero-Engine Ltd., Xi'an 710021, China
}

Correspondence should be addressed to Kun Chen; chenkun@mail.xjtu.edu.cn

Received 7 April 2021; Revised 17 August 2021; Accepted 5 October 2021; Published 16 November 2021

Academic Editor: Athanasios Chasalevris

Copyright (C) $2021 \mathrm{Li}-\mathrm{li} \mathrm{Li}$ et al. This is an open access article distributed under the Creative Commons Attribution License, which permits unrestricted use, distribution, and reproduction in any medium, provided the original work is properly cited.

\begin{abstract}
Aiming at the optimization problem of multiple objectives with contradictions and conflicts in the process of allocating the tolerance for complex products, taking advantage of the features of coordinating, and balancing contradictions and conflicts of cooperative game theory, this paper uses cooperative game theory to solve the multiobjective optimization problem of tolerance allocation. The quality requirements and cost requirements of assembly products are used as the game decision parties, and the fuzzy clustering method is used to group the design variables of tolerance allocation problem of the steam turbine to form the strategic space of game parties. Take the quality level and cost level of the assembly product as the optimization goals, complete the calculation of the utilities of the two game parties, and establish the multiobjective optimization model of tolerance allocation based on cooperative game theory. Finally, the Shapley value method based on cooperative game theory, the Nash equilibrium method based on noncooperative game theory, and the traditional single-objective optimization method with the quality as the constraint and the cost as the optimization objective are used to solve the tolerance allocation problem of steam turbine. The solution results show that the method of cooperative game realized the balance, coordination, and comprehensive optimization of the quality and cost from the perspective of collective interests, overcame the shortcomings of the traditional single-objective optimization method, and obtained better result than the Nash equilibrium method.
\end{abstract}

\section{Introduction}

Tolerance allocation is a core issue of tolerance design theory; it mainly studies how to scientifically and reasonably allocate the design tolerance of the closed ring to each component ring [1] and realizes the balanced coordination and comprehensive optimization of some indicators such as processing cost of the product, assembly quality, and assembly robustness under the premise of ensuring certain assembly success rate [1]. The key issue of tolerance allocation is how to establish a balance among its contradictory and conflicting goals, especially between the quality and cost, consider the mutual influence and conflict between the two goals, and finally get a scientific, reasonable, and balanced and coordinated tolerance allocation optimization program. At present, the widely used tolerance allocation method is single-objective optimization method with quality as the constraint and cost as the optimization goal $[2,3]$, or both quality and cost are considered, and a multiobjective comprehensive weighted evaluation function is constructed to complete the establishment of the tolerance allocation optimization model. In addition, various analytical methods or some intelligent optimization algorithms are adopted to solve [4].

Over these years, many optimization algorithms have been developed, divided into deterministic algorithms and stochastic algorithms [5]. Traditional optimization algorithms are usually deterministic, because they run multiple times to output the same results. Therefore, a majority of mathematical programming methods are based on the gradient of the objective function and constraint conditions 
[5]. Many researchers have proved the applicability of deterministic optimization methods, such as linear programming [6] and nonlinear programming [7], which are used to solve the most basic tolerance allocation problem [8]. Later, due to the advantages that the stochastic algorithms are not restricted by the gradient information of the objective function, compared with the deterministic algorithms, they can handle more complex tolerance allocation models, so they have been more widely used. Among the stochastic algorithms, there are some more common algorithms, such as simulated annealing (SA) [9], genetic algorithm (GA) [10], particle swarm optimization (PSO) [11], and ant colony algorithm; besides, some less common algorithms are also used for tolerance-cost optimization, such as the imperial competition algorithm [12], self-organizing migration algorithm [13], bat algorithm [14], artificial bee colony algorithm [15], and cuckoo search [16]. In addition, the application of hybrid algorithm in the field of tolerance allocation is also studied. Hybrid algorithm mainly combines stochastic and deterministic or another stochastic optimization algorithm to improve the optimization effect [17]. Although the above intelligent algorithms have certain advantages, sometimes the calculation efficiency is not high and the construction of the evaluation function is difficult. Moreover, the traditional tolerance allocation method which takes quality as the constraint and takes the cost as the optimal goal is difficult to find a scientific and reasonable equilibrium solution among multiple goals. The tolerance allocation method, which relies on experience to determine the weight of quality and cost and form a comprehensive evaluation function of quality and cost, cannot scientifically measure the mutual influence and conflict among different goals.

The abovementioned algorithms can effectively solve singleobjective or multiobjective optimization problems, such as particle swarm optimization algorithm of solving multiobjective optimization problems, but it is difficult to deal with the optimization problem of multiple objectives with contradictions and conflicts. The essence of game theory solving the problem of multiobjective optimization is to find a balanced solution among multiple goals with contradictions and conflicts, and to achieve the balanced coordination and comprehensive optimization of multiple goals. Therefore, game theory has been well applied in all walks of life. Zhu and Başar studied game theory and realized the tradeoff between security and usability of computing systems [18]. In the book of game theory for wireless communications and networking, game theory appeared as a new tool for the wireless engineer to tackle spectrum sharing, power control, resource allocation, transmission strategy, and security and network etiquette issues [19]. It can be seen that game theory has achieved good optimization effects in the allocation of resources and the balance of objectives.

The study found that the tolerance allocation optimization problem is a multiobjective optimization problem with contradictions and conflicts among multiple objectives. Therefore, in order to meet the continuous increase need of users for the quality and the continuous decrease need of enterprises for the manufacturing cost of complex products, this paper introduces the cooperative game theory and makes the most of its characteristics of coordination, balancing conflicts and contradictions to establish a set of tolerance allocation multiobjective optimization models based on cooperative game theory. By solving and analyzing the game utility matrix to obtain the tolerance allocation optimization program, we can realize the comprehensive optimization and balanced coordination of product quality and cost and achieve the multiobjective optimization goals of high quality and low cost for complex products.

\section{Cooperative Game Decision-Making Method of Solving the Multiobjective Optimization Problem of Steam Turbine Tolerance Allocation}

The steam turbine is a typical representative of complex products and major equipment. It not only has a large number of parts, but also has a large size and weight. More importantly, it has very strict requirements on the accuracy of the flow gap between the moving and static parts. If the gap is too large, it is not conducive to the efficiency of power generation of steam turbine; however, if the gap is too small, it is not conducive to the safe operation of the steam turbine. Therefore, the steam turbine is not only a complex and important equipment, but also a country's important equipment, and its assembly quality and manufacturing cost cannot be ignored. In addition to ensuring the flow gap of the steam turbine, respectively, by certain processing and assembly processes, more importantly, it is also necessary to optimize the tolerance allocation during the initial tolerance design process, which can ensure that the flow gap fluctuates within the design tolerance range and achieve the improvement of the flow gap assembly qualification rate, the enhancement of the assembly robustness, and the optimization of the manufacturing cost. As a core technology of tolerance design theory, tolerance distribution determines the assembly quality and manufacturing cost of steam turbines fundamentally. When assigning tolerances for steam turbines, quality and cost are two indicators that cannot be ignored; they are also two contradictory and conflicting goals. Therefore, the essence of the tolerance distribution optimization problem of steam turbines is the multiobjective optimization problem with contradictions and conflicts in the tolerance distribution of complex products. Game theory has the advantages of reconciling conflicts and contradictions, as well as flexible and convenient modeling characteristics; it is suitable for solving multiobjective optimization problems in the engineering field where contradictions and conflicts exist. Therefore, this paper introduces game theory and establishes a set of multiobjective optimization models of steam turbine tolerance allocation based on cooperative game theory.

\subsection{Construction of the Cooperative Game Model of Steam Turbine Tolerance Distribution}

2.1.1. Modeling Process. The flow gap is an important assembly quality indicator of the steam turbine, and it is also the final quality indicator to be guaranteed during the 
assembly process of the steam turbine. Besides, the flow gap is also a terminal closed ring formed by manufacturing deviation transmission, coupling, and accumulation. The remaining dimensions that form the closed ring (the flow gap) of the steam turbine are the component ring dimensions. The tolerances of these component ring dimensions are the design variables involved in the tolerance distribution of the steam turbine. The optimization goal of the tolerance distribution is the assembly quality and manufacturing cost of the steam turbine. The design tolerance of the flow gap is allocated to each component ring constituting the flow gap of the steam turbine, and a multiobjective optimization model of steam turbine tolerance allocation that takes into account quality and cost is established, as shown in the following equation:

$$
\begin{cases}\min & \left\{\begin{array}{l}
T_{0}=T_{0}\left(T_{1}, T_{2}, \ldots, T_{n}\right), \\
C=C\left(T_{1}, T_{2}, \ldots, T_{n}\right),
\end{array}\right. \\
\text { s.t. } & \left\{\begin{array}{l}
l_{i} \leq T_{i} \leq h_{i} 1 \leq i \leq n, \\
l_{0} \leq T_{0} \leq h_{0},
\end{array}\right.\end{cases}
$$

where $L=\left(l_{1}, l_{2}, \ldots, l_{n}\right)$ and $H=\left(h_{1}, h_{2}, \ldots, h_{n}\right)$ are the upper and lower deviation of each component ring tolerance and $l_{0}$ and $h_{0}$ are the design tolerance of assembly quality (the closed ring).

Figure 1 shows the construction process of the optimization model of steam turbine tolerance allocation based on cooperative game theory. We took assembly quality and processing cost as the two game parties, adopted the fuzzy cluster analysis method to determine the strategy space of each game party, assembly quality level, and processing cost level as the optimization goals, calculated the utility of the two game parties, and established a set of tolerance distribution multiobjective optimization models for the steam turbines based on the cooperative game theory. In the game model, the strategies of each player are independent of each other and do not interfere with each other. Therefore, when the game model is established, each player must be divided into its own strategy vector. When optimizing tolerance allocation that takes into account both quality and cost goals, the design tolerances of each component ring are the design variables shared by the quality and cost optimization objective functions. Therefore, according to the relationship between the design variables and the game parties, the design variables, which are more closely related to the quality game player, are assigned to form the strategy space of the quality game player, and the remaining design variables become the strategy space of the cost game player. Fuzzy cluster analysis can analyze the relationship between the samples and categories, describe the relationship between the samples and each category, divide the samples into the corresponding number of groups according to the relationship between the samples and each category, and finally divide the samples into the corresponding categories. Therefore, the fuzzy cluster analysis method is used to solve the degree of influence of design variables on each game party, and the design variables that are closely related to the quality game party are allocated to the quality game party, and the remaining design variables are allocated to the cost game party, form the strategic space of each game party, and finally complete the establishment of the game model of steam turbine tolerance allocation.

2.1.2. Calculation of the Game Utility. The manufacturing deviation model and the manufacturing cost function are used to calculate the utility of the quality and cost game parties. In order to facilitate the comparison of the utility of the game parties, the calculation results of the game utility of each game party are standardized in this paper [20].

2.1.3. Determination of the Game Strategy. Discretize all the design variables (that are the design tolerances of component ring dimensions). The specific method is to divide the design tolerance of each component ring dimension into several quality levels with a certain step length, so as to obtain the discrete value of the design variables of each component ring dimension [20]. This paper uses fuzzy clustering theory to complete the grouping of design variables and determine the strategy for each game party:

(1) $\delta=\left(\delta_{1}, \delta_{2}, \ldots, \delta_{n}\right)$ are the design variables used for classification, the design variable $\delta_{i}$ is characterized by $\left(\delta_{i, 1}, \delta_{i, 2}, \ldots, \delta_{i, m}\right), \delta_{i, j}$ is the distribution factor, which represents the degree of connection between the design variable $i$ and the target $j$, and $m$ is the number of targets to be optimized. The game parties in this paper are the assembly product quality requirements and the product manufacturing cost requirements. The design variables used for tolerance allocation are constituted by the design tolerances of each component ring, so $T=\left(T_{1}, T_{2}, \ldots, T_{n}\right)$ are the design variables used for classification, and $T_{i}$ is characterized by the allocation factor $\left(T_{i, 1}, T_{i, 2}\right)$.

(2) This article uses standard deviation transformation to eliminate the influence of dimensions. The transformation formula is shown as follows:

$$
\begin{aligned}
\sigma_{I, J}^{\prime} & =\frac{\sigma_{i, j}-\overline{\sigma_{j}}}{s_{j}} \quad(i=1,2, \ldots, n, j=1,2, \ldots, m), \\
\overline{\sigma_{j}} & =\frac{1}{n} \sum_{i=1}^{n} \sigma_{i, j}, \\
s_{j} & =\sqrt{\frac{1}{n} \sum_{i=1}^{n}\left(\sigma_{i, j}-\overline{\sigma_{j}}\right)^{2}} .
\end{aligned}
$$

(3) Absolute value subtraction method is commonly used to calculate the degree of similarity between classified objects, and fuzzy similarity matrix $R=$ $\left[r_{i, j}\right]_{n \times n}, 0 \leq r_{i, j} \leq 1, i, \quad j=1,2, \ldots, n, r_{i, j} \quad$ indicates the degree of similarity between the classified objects $x_{i}$ and $x_{j}$. The specific calculation formula is shown as follows: 


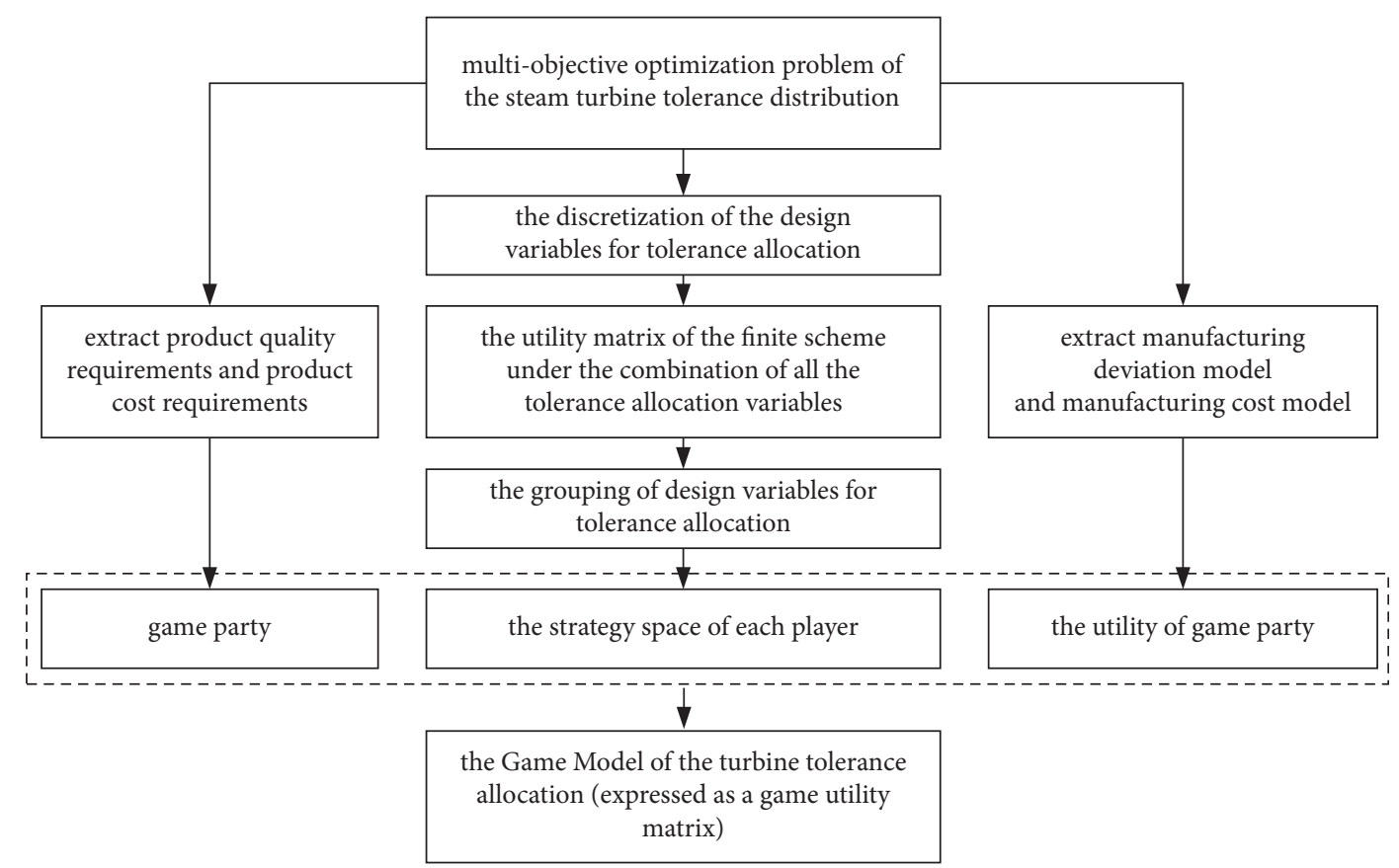

FIGURE 1: Construction process of optimization model of steam turbine tolerance allocation based on cooperative game theory.

$$
r_{i, j}=\left\{\begin{array}{l}
1 i=j, \\
1-M \sum_{k=1}^{2}\left|\sigma_{i, j}{ }^{\prime}-\sigma_{i, k}{ }^{\prime}\right| \quad i \neq j .
\end{array}\right.
$$

The value of $M$ is appropriately selected to make $r_{i, j}$ within the range: $0 \leq r_{i, j} \leq 1$.

(4) Use the square self-synthesis method to get the transitive closure matrix $R^{*}$ of $R$; that is, the fuzzy equivalent matrix $R^{*}, R^{2}, R^{4}, \ldots, R^{2 k}$ are calculated from $R$, until the $R^{2 k}=R^{k} \circ R^{k}=R^{k}$ is met, the symbol of “。” represents Boolean operation, and the basic rules of operation are shown as follows:assume that $\quad R=\left[\begin{array}{ll}a & b \\ c & d\end{array}\right] ; \quad$ then $\quad R^{2}=R \circ R=$ $\left[\begin{array}{ll}(a \wedge a) \vee(b \wedge c) & (a \wedge b) \vee(b \wedge d) \\ (c \wedge a) \vee(d \wedge c) & (c \wedge b) \vee(d \wedge d)\end{array}\right], \quad a \vee b=\max (a, b)$, $a \wedge b=\min (a, b) . R^{*}=R^{2 k}=R^{k}$ is the fuzzy equivalent matrix [18].

(5) The calculation of the $\lambda$-cut matrix $R_{\lambda}$ is completed based on the fuzzy equivalent matrix $R^{*}$, and a $\lambda$ value is given and satisfies the formula shown as follows:

$$
r_{i, j}^{*}= \begin{cases}1, & r_{i, j}^{*} \geq \lambda \\ 0, & r_{i, j}^{*}<\lambda\end{cases}
$$

where $r_{i, j}^{*}$ is the element of the fuzzy equivalence matrix $R^{*}$. According to the number of players in the tolerance allocation game model, select the appropriate $\lambda$ value that can divide all design variables into corresponding groups.
(6) The tolerance allocation game model in this paper has only two game parties. Therefore, the fuzzy cluster analysis method only needs to divide all design variables into two groups and assign the design variables that are closely related to the quality game party to the quality game party and form the strategy space of the quality game party [20], and the remaining design variables become the strategy space of the cost game party. The solution results of each game party's strategy are shown in the following formula:

$$
\begin{array}{r}
s_{1}=\left(s_{1,1}, s_{1,2}, \ldots, s_{1, k_{1}}\right) ; s_{2}=\left(s_{2,1}, s_{2,2}, \ldots, s_{2, k_{2}}\right) \\
k_{1}+k_{2}=n .
\end{array}
$$

\section{Solving Method of Steam Turbine Tolerance Allocation Based on Cooperative Game Theory}

The significant advantage of the Shapley value method is that it can effectively measure the mutual influence and conflict between the game parties and realize the comprehensive optimization and balanced coordination of multiple optimization goals. The Shapley value method has the unique solution result and its solution is the Pareto optimal solution. Therefore, the Shapley value method in the cooperative game solving method is widely used [20]. Therefore, this paper used the Shapley method in cooperative game theory to solve the multiobjective optimization problem of the steam turbine tolerance allocation.

The optimal allocation plan obtained by the Shapley value method can be accepted to all players. This allocation plan takes into account the contribution or influence of each player in the 
cooperative game. $\quad x=\left(x_{1}, x_{2}, \ldots, x_{n}\right)=$ $\left(\varphi_{1}(\nu), \varphi_{2}(\nu), \ldots, \varphi_{n}(\nu)\right)$ is a distribution plan of the alliance game, the calculation method of $x_{i}$ is $x_{i}=\varphi_{i}(\nu)=$ $\sum_{S \subseteq N}(|S|-1) !(n-|S|) ! / n ![\nu(S)-\nu(S /\{i\})]$, and Figure 2 $I \in S$

shows the solving process of the game model of the steam turbine tolerance allocation by Shapley value method. $\nu(\{i\}), v(S), v(S /\{i\})$ are the characteristic functions of each alliance; $(\nu(\{1\}), v(\{2\}), \ldots, \nu(\{i\}))$ is the gravity center of the characteristic function of each player; $\Phi=\left(\varphi_{1}, \varphi_{2}, \ldots, \varphi_{n}\right)$ is the Shapley value vector; $U=\left(u_{1}, u_{2}, \ldots, u_{n}\right)$ is the vector of utility combinations, $d=\|U-\Phi\|$ is the norm. When $\exists\left(u_{1}^{*}, u_{2}^{*}, \ldots, u_{n}^{*}\right), \quad$ make $d\left(u_{1}^{*}, u_{2}^{*}, \ldots, u_{n}^{*}\right)=d_{\text {min }}$, $\left(u_{1}^{*}, u_{2}^{*}, \ldots, u_{n}^{*}\right)$ is the optimal utility vector, and $\left(s_{1}^{*}, s_{2}^{*}, \ldots, s_{n}^{*}\right)$ is corresponding optimal strategy combination.

\section{Noncooperative Game Solution Method Based on Nash Equilibrium}

The players participating in the noncooperative game only proceed from their own interests and seek the most advantageous strategy for themselves, without considering the interests of other players. The result obtained by the noncooperative game method is the Nash equilibrium solution, which is defined as $G=\left\{P_{i} ; S_{i} ; u_{i}(i=1,2, \ldots, n)\right\}$, a game with $n$ players, for each game player $i, s_{-i}^{*}=\left(s_{1}^{*}, \ldots, s_{i-1}^{*}, s_{i+1}^{*}\right.$, $\left.\ldots, s_{n}^{*}\right)$ is the given strategy combination of other players, $s_{i}^{*}$ is the optimal strategy of the player $P_{i}$ based on this strategy combination, namely, $u_{i}\left(s_{i}^{*}, s_{-i}^{*}\right) \leq u_{i}\left(s_{i}, s_{-i}^{*}\right), \quad \forall i, \forall s_{i} \in S_{i}$, the strategy combination of $s^{*}=\left(s_{1}^{*}, \ldots, s_{i}^{*}, \ldots, s_{n}^{*}\right)$ is called a Nash equilibrium, its characteristic is that, at the equilibrium point, all players are willing to follow their own strategies in order not to reduce their own profits. $u_{i}\left(s_{i}^{*}, s_{-i}^{*}\right) \leq u_{i}\left(s_{i}, s_{-i}^{*}\right)$ is a weak Nash equilibrium. For strong Nash equilibrium, the above formula of $u_{i}\left(s_{i}^{*}, s_{-i}^{*}\right) \leq u_{i}$ $\left(s_{i}, s_{-i}^{*}\right)$ needs to be changed to: $u_{i}\left(s_{i}^{*}, s_{-i}^{*}\right)<u_{i}$ $\left(s_{i}, s_{-i}^{*}\right), \quad \forall i, \forall s_{i} \in S_{i}$, and $s_{i} \neq s_{i}^{*}$; at this time, each player has a unique optimal strategy.

The solution result of the Nash equilibrium method is a local optimal solution, and this local optimal solution is not necessarily the Pareto optimal solution. If the games can cooperate from the perspective of collective interests, the Nash equilibrium solution still has some space for optimization [20].

\section{Tolerance Allocation Model with the Lowest Cost Based on Quality Constraints}

The most commonly used method in traditional tolerance allocation optimization is the allocation method with the optimal cost, and quality as the constraint. The tolerance distribution optimization model is shown in the following formula:

$$
\begin{cases}\min & C=C\left(T_{1}, T_{2}, \ldots, T_{n}\right), \\
\text { s.t } \quad\left\{\begin{array}{l}
T_{0}=T_{0}\left(T_{1}, T_{2}, \ldots, T_{n}\right), \\
l_{i} \leq T_{i} \leq h_{i} 1 \leq i \leq n, \\
l_{0} \leq T_{0} \leq h_{0}
\end{array}\right.\end{cases}
$$

$$
\begin{aligned}
& \text { The process of solving the game model of the steam turbine } \\
& \text { tolerance allocation by Shapley value method } \\
& \text { Determine the set of players' alliances and their subsets:N; } \mathrm{S} \subseteq \mathrm{N} \\
& \text { Calculate the characteristic function of each } \\
& \text { alliance: } v(\{i\}) ; v(S) ; v(S \backslash\{i\}) \\
& \downarrow \\
& \text { The gravity center of the characteristic function of each } \\
& \text { player: }(v(\{1\}) ; v(\{2\}) ; \ldots v(\{i\})) \\
& \text { The Shapley value vector calculation } \\
& \varphi_{1}(v)=\sum_{\substack{S \subseteq N \\
I \in S}} \frac{(|S|-1) !(n-|S|) !}{n !}[v(S)-v(S \backslash\{i\})] \\
& \downarrow \\
& \text { Calculate the norm of any combination of utility and the } \\
& \text { Shapley value vector: } d=\|U-\Phi\| \\
& \downarrow \\
& \text { the optimization result of the Shapley value method: } \\
& \text { Optimal utility: }\left(u_{1}^{*}, u_{2}^{*}, \ldots, u_{n}^{*}\right) \\
& \text { Optimal strategy: }\left(S_{1}^{*}, S_{2}^{*}, \ldots, S_{n}^{*}\right)
\end{aligned}
$$

Figure 2: The process of solving the game model of the steam turbine tolerance allocation by Shapley value method.

where $L=\left(l_{1}, l_{2}, \ldots, l_{n}\right)$ and $H=\left(h_{1}, h_{2}, \ldots, h_{n}\right)$ are the upper and lower deviation of the tolerance of each component ring and $l_{0}$ and $h_{0}$ are the assembly quality constraint of the product.

\section{Example Analysis of the Steam Turbine Tolerance Distribution}

The flow gap between the moving and static parts of the steam turbine is an important indicator of the assembly quality of the steam turbine. It is also the last quality indicator to be guaranteed during the assembly process of the steam turbine. It is also a terminal closed ring formed by the transmission, coupling, and accumulation of manufacturing deviations; the blade tip seal gap and the baffle seal gap of the steam turbine horizontally divided surface are shown in Figure 3. The plane dimension chain of the flow gap of the horizontally divided surface of the steam turbine and the meaning of each component ring and closed ring in the dimension chain are shown in Figures 4 and 5. The guarantee of the flow gap needs to be ensured by certain machining and assembly processes during the process of machining and assembly, respectively; more importantly, it is also necessary to optimize the tolerance allocation to ensure that the flow gap fluctuates within its tolerance range during the initial tolerance design process and realize the improvement of the assembly quality of the steam turbine and the optimization of the manufacturing cost. Therefore, carrying out the related research work on the multiobjective optimization of the tolerance distribution of complex products can provide reference and guidance for the guarantee of the flow gap of the steam turbine, the improvement of the assembly quality, and the optimization of the manufacturing cost. 


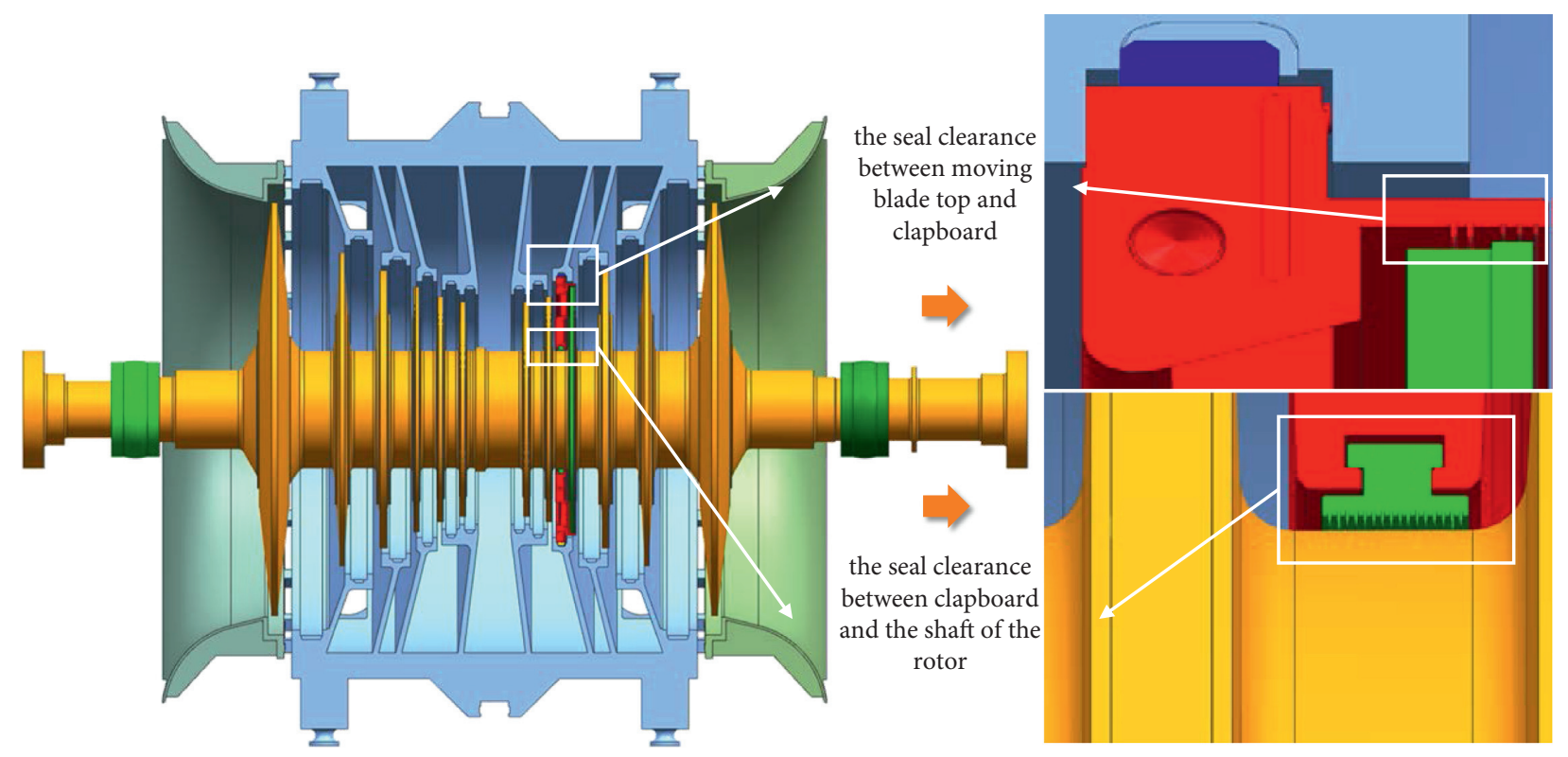

FIgURe 3: The flow gap of the steam turbine.

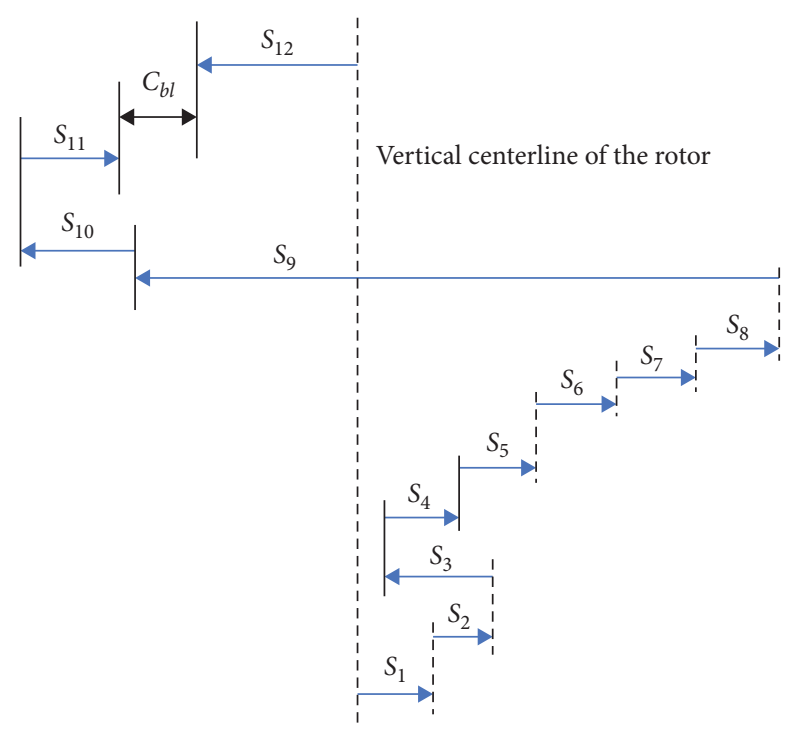

Figure 4: The plane dimension chain of the flow gap of the horizontally divided surface of the steam turbine.

6.1. Determination of the Multiobjective Optimization Model considering Both Quality and Cost. Based on the assembly method between the closed ring and the component ring of the dimensional chain and the tolerance-cost index model, the optimized mathematical model of "quality-cost" was established. $\xi_{i}$ is the transmission coefficient of each component ring, and $b_{i}$ is the cost factor associated with the tolerance of each component ring. Generally speaking, the greater the influence of tolerance design variables $T_{i}$ on the tolerance $T_{0}$ of the closed ring, the greater the $\left|\xi_{i}\right|$. The greater the influence of tolerance design variables $T_{i}$ on the machining cost of the tolerance $T_{0}$ of the closed ring, the smaller the $b_{i} . \quad \xi_{3}=\xi_{9}=\xi_{10}=\xi_{12}=1, \xi_{1}=\xi_{2}=\xi_{4}=\xi_{7}$ $=\xi_{8}=\xi_{11}=-1$; besides, assume that $a_{i}=1, i=$
$1,2,3,4,7,8,9,10,11,12 ; b_{1}=b_{2}=0.1, b_{3}=b_{4}=0.2, b_{7}=$ $b_{8}=0.3, b_{9}=b_{10}=0.4, b_{11}=b_{12}=0.5$. For different dimensions of the component ring, if their machining costs are different, then $a_{i}$ and $b_{i}$ are also different. As long as there are enough historical statistics of tolerance and cost, the values of $a_{i}$ and $b_{i}$ can be calculated by curve fitting. Because the research focus of this article is not the tolerance-cost model, but for the same tolerance-cost model, which optimization method is better? Therefore, this article did not research too much on the establishment of tolerance-cost model. In order to facilitate calculation and comparison, this article assumed the values of $a_{i}$ and $b_{i}$. In the formula, both $a$ and $b$ are constant coefficients greater than 0 . The design range of the flow gap is $0.25 \leq T_{b l} \leq 0.55$. The sizes of S5 and S6 are used for repairing, so when we allocate tolerances, there is no need to assign a tolerance for them, so $i \neq 5,6$.

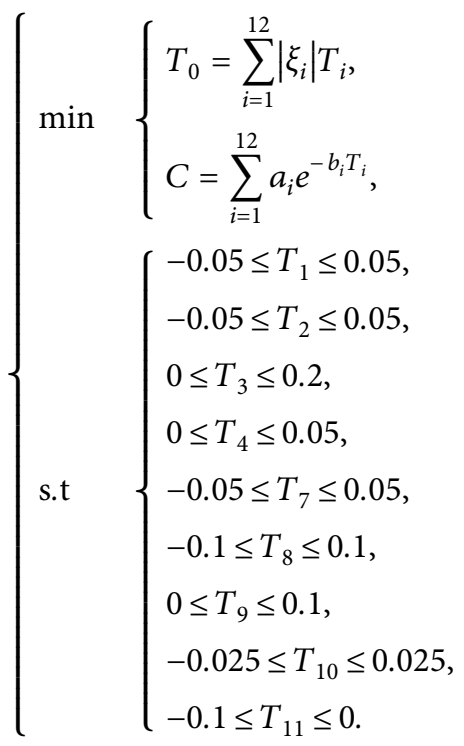




\begin{tabular}{|c|c|c|c|c|}
\hline $\begin{array}{l}\text { Composition } \\
\text { ring name }\end{array}$ & $\begin{array}{l}\text { Nominal } \\
\text { size }\end{array}$ & $\begin{array}{l}\text { Lower } \\
\text { deviation }\end{array}$ & $\begin{array}{l}\text { Upper } \\
\text { deviation }\end{array}$ & meaning \\
\hline S1 & 0.15 & -0.05 & 0.05 & $\begin{array}{l}\text { vector from the vertical centerline of the rotor to the vertical centerline of } \\
\text { the inner cylinder }\end{array}$ \\
\hline S2 & 0 & -0.05 & 0.05 & $\begin{array}{l}\text { vector from the vertical centerline of the inner cylinder to the centerline } \\
\text { of the keyway at the bottom of the inner cylinder (symmetry 0.1) }\end{array}$ \\
\hline S3 & 50 & 0 & 0.2 & $\begin{array}{c}\text { vector from the center line of the keyway at the bottom of the inner } \\
\text { cylinder to the left side of the keyway }\end{array}$ \\
\hline S4 & 0 & 0 & $0.03-0.05$ & $\begin{array}{l}\text { vector from the left side of the keyway at the bottom of the inner } \\
\text { cylinder to the left side of the inner cylinder of the positioning key }\end{array}$ \\
\hline S5 & 50 & 0 & 3 (repair) & $\begin{array}{l}\text { the vector from the left side of the inner cylinder end of the positioning } \\
\text { key to the centerline of the inner cylinder end of the positioning key }\end{array}$ \\
\hline S6 & 0 & -3 & 3 (repair) & $\begin{array}{l}\text { vector from the center line of the cylinder end of the positioning key to } \\
\text { the center line of the spacer end of the positioning key }\end{array}$ \\
\hline S7 & 0 & -0.05 & 0.05 & $\begin{array}{l}\text { the vector from the centerline of the spacer end of the positioning key to } \\
\text { the vertical centerline of the outer ring of the spacer (symmetry 0.1) }\end{array}$ \\
\hline S8 & 0 & -0.1 & 0.1 & $\begin{array}{l}\text { vector from the vertical centerline of the outer ring of the spacer to the } \\
\text { vertical centerline of the inner ring of the spacer (concentricity } 0.2 \text { ) }\end{array}$ \\
\hline S9 & 1038 & 0 & 0.1 & the inner circle radius vector of the spacer \\
\hline S10 & 10 & -0.025 & 0.025 & vector from inner circle of the spacer to the T-slot convex surface \\
\hline S11 & 28.5 & -0.05 & 0.05 & $\begin{array}{l}\text { vector from the T-block's concave circular surface of the left arc section } \\
\text { of the spacer steam seal to the top of the steam seal tooth }\end{array}$ \\
\hline S12 & 1000 & -0.1 & 0 & the radius vector of the rotor impeller groove \\
\hline $\mathrm{Cbl}$ & 0 & 0.25 & 0.55 & the left seal clearance of spacer \\
\hline
\end{tabular}

Figure 5: The meaning of the component rings and closed ring in the dimension chain of Figure 4.

\subsection{Establishment of the Game Model of Steam Turbine} Tolerance Allocation. In this paper, the fuzzy clustering method was used to divide the design variables into two groups to form the strategy space for each game party. The specific steps are shown as follows:

(1) All design variables are $T=\left\{T_{1}, T_{2}, T_{3}, T_{4}, T_{7}\right.$, $\left.T_{8}, T_{9}, T_{10}, T_{11}, T_{12}\right\}, T_{i}$ is characterized by distribution factor $\left(T_{i, 1}, T_{i, 2}\right)$, and $T_{i, 1}$ and $T_{i, 2}$ are used to measure the degree of influence on the two optimization goals by tolerance design variables $T_{i}$. In this paper, the closed-loop tolerance is used to characterize the assembly quality, $\xi_{i}$ is not only the transfer coefficient in the solution equation of the closed-loop tolerance, but also the distribution factor of the assembly quality game $\mathrm{P} 1$; namely, $T_{i, 1}=\xi_{i}, \xi_{i}$ reflects the influence degree of the design tolerance of each component ring on the tolerance $T_{0}$ of the closed ring, $T_{0}$ is the closed-loop tolerance calculated after the tolerance distribution is completed, and its calculation result needs to be compared with the design value $T_{b l}$ of the closed ring tolerance originally designed in the enterprise. $T_{b l}$ is the design value of the tolerance of the closed loop in the dimension chain of Figure 4, and its range is $0.25 \leq T_{b l} \leq 0.55 ; b_{i}$ is the cost coefficient related to the tolerance of each component ring, and it is also the allocation factor of the cost game party P2, namely, $T_{i, 2}=b_{i}$. It reflects the degree of influence of the tolerance of each component ring on the final manufacturing cost. Based on the above theory, the distribution factor of each game party could be obtained and shown as follows:

$$
\begin{aligned}
\left(T_{1,1}, T_{1,2}\right) & =(-1,0.1) ; \\
\left(T_{2,1}, T_{2,2}\right) & =(-1,0.1) ; \\
\left(T_{3,1}, T_{3,2}\right) & =(1,0.2) ; \\
\left(T_{4,1}, T_{4,2}\right) & =(-1,0.2) ; \\
\left(T_{7,1}, T_{7,2}\right) & =(-1,0.3) ; \\
\left(T_{8,1}, T_{8,2}\right) & =(-1,0.3) ; \\
\left(T_{9,1}, T_{9,2}\right) & =(1,0.4) ; \\
\left(T_{10,1}, T_{10,2}\right) & =(1,0.4) ; \\
\left(T_{11,1}, T_{11,2}\right) & =(-1,0.5) ; \\
\left(T_{12,1}, T_{12,2}\right) & =(1,0.5) .
\end{aligned}
$$

(2) In order to eliminate the influence of magnitude, standard deviation transformation was used to complete the data standardization. The new distribution factor of each game party was shown as follows: 


$$
\begin{aligned}
\left(T_{1,1}, T_{1,2}\right) & =(-0.8165,-1.4142) ; \\
\left(T_{2,1}, T_{2,2}\right) & =(-0.8165,-1.4142) ; \\
\left(T_{3,1}, T_{3,2}\right) & =(1.2247,-0.7071) ; \\
\left(T_{4,1}, T_{4,2}\right) & =(-0.8165,-0.7071) ; \\
\left(T_{10,1}, T_{10,2}\right) & =(1.2247,0.7071) ; \\
\left(T_{11,1}, T_{11,2}\right) & =(-0.8165,1.4142) ; \\
\left(T_{12,1}, T_{12,2}\right) & =(1.2247,1.4142) ; \\
\left(T_{7,1}, T_{7,2}\right) & =(-0.8165,0) ; \\
\left(T_{8,1}, T_{8,2}\right) & =(-0.8165,0) ; \\
\left(T_{9,1}, T_{9,2}\right) & =(1.2247,0.7071) .
\end{aligned}
$$

(3) The absolute value subtraction method was used for calibration, and the fuzzy similarity matrix was shown as follows:

$$
R=\left[\begin{array}{cccccccccc}
1 & 1 & 0.7252 & 0.9293 & 0.8586 & 0.8586 & 0.5838 & 0.5838 & 0.7172 & 0.5130 \\
1 & 1 & 0.7252 & 0.9293 & 0.8586 & 0.8586 & 0.5838 & 0.5838 & 0.7172 & 0.5130 \\
0.7252 & 0.7252 & 1 & 0.7959 & 0.7252 & 0.7252 & 0.8586 & 0.8586 & 0.5838 & 0.7879 \\
0.9293 & 0.9293 & 0.7959 & 1 & 0.9293 & 0.9293 & 0.6545 & 0.6545 & 0.7879 & 0.5838 \\
0.8586 & 0.8586 & 0.7252 & 0.9293 & 1 & 1 & 0.7252 & 0.7252 & 0.8586 & 0.6545 \\
0.8586 & 0.8586 & 0.7252 & 0.9293 & 1 & 1 & 0.7252 & 0.7252 & 0.8586 & 0.6545 \\
0.5838 & 0.5838 & 0.8586 & 0.6545 & 0.7252 & 0.7252 & 1 & 1 & 0.7252 & 0.9293 \\
0.5838 & 0.5838 & 0.8586 & 0.6545 & 0.7252 & 0.7252 & 1 & 1 & 0.7252 & 0.9293 \\
0.7172 & 0.7172 & 0.5838 & 0.7879 & 0.8586 & 0.8586 & 0.7252 & 0.7252 & 1 & 0.7959 \\
0.5130 & 0.5130 & 0.7879 & 0.5838 & 0.6545 & 0.6545 & 0.9293 & 0.9293 & 0.7959 & 1
\end{array}\right]
$$

(4) It was found that $R^{*}=R^{6}=R^{3}$ by calculation.

Therefore, the obtained fuzzy equivalent matrix was

$$
R^{*}=\left[\begin{array}{cccccccccc}
1 & 1 & 0.7959 & 0.9293 & 0.9293 & 0.9293 & 0.7959 & 0.7959 & 0.8586 & 0.7959 \\
1 & 1 & 0.7959 & 0.9293 & 0.9293 & 0.9293 & 0.7959 & 0.7959 & 0.8586 & 0.7959 \\
0.7959 & 0.7959 & 1 & 0.7959 & 0.7959 & 0.7959 & 0.8586 & 0.8586 & 0.7959 & 0.8586 \\
0.9293 & 0.9293 & 0.7959 & 1 & 0.9293 & 0.9293 & 0.7959 & 0.7959 & 0.8586 & 0.7959 \\
0.9293 & 0.9293 & 0.7959 & 0.9293 & 1 & 1 & 0.7959 & 0.7959 & 0.8586 & 0.7959 \\
0.9293 & 0.9293 & 0.7959 & 0.9293 & 1 & 1 & 0.7959 & 0.7959 & 0.8586 & 0.7959 \\
0.7959 & 0.7959 & 0.8586 & 0.7959 & 0.7959 & 0.7959 & 1 & 1 & 0.7959 & 0.9293 \\
0.7959 & 0.7959 & 0.8586 & 0.7959 & 0.7959 & 0.7959 & 1 & 1 & 0.7959 & 0.9293 \\
0.8586 & 0.8586 & 0.7959 & 0.8586 & 0.8586 & 0.8586 & 0.7959 & 0.7959 & 1 & 0.7959 \\
0.7959 & 0.7959 & 0.8586 & 0.7959 & 0.7959 & 0.7959 & 0.9293 & 0.9293 & 0.7959 & 1
\end{array}\right] .
$$

(5) Take $\lambda$ as 0.8 , and the $\lambda$ cut matrix $R_{\lambda}$ was 


$$
R_{\lambda}=\left[\begin{array}{llllllllll}
1 & 1 & 0 & 1 & 1 & 1 & 0 & 0 & 1 & 0 \\
1 & 1 & 0 & 1 & 1 & 1 & 0 & 0 & 1 & 0 \\
0 & 0 & 1 & 0 & 0 & 0 & 1 & 1 & 0 & 1 \\
1 & 1 & 0 & 1 & 1 & 1 & 0 & 0 & 1 & 0 \\
1 & 1 & 0 & 1 & 1 & 1 & 0 & 0 & 1 & 0 \\
1 & 1 & 0 & 1 & 1 & 1 & 0 & 0 & 1 & 0 \\
0 & 0 & 1 & 0 & 0 & 0 & 1 & 1 & 0 & 1 \\
0 & 0 & 1 & 0 & 0 & 0 & 1 & 1 & 0 & 1 \\
1 & 1 & 0 & 1 & 1 & 1 & 0 & 0 & 1 & 0 \\
0 & 0 & 1 & 0 & 0 & 0 & 1 & 1 & 0 & 1
\end{array}\right] .
$$

Therefore, the design variables were grouped finally as $\left\{T_{1}, T_{2}, T_{4}, T_{7}, T_{8}, T_{11}\right\},\left\{T_{3}, T_{9}, T_{10}, T_{12}\right\}$.

(6) Generally speaking, the greater the impact of tolerance design variables $T_{i}$ on the tolerance $T_{0}$ of the closed loop, the greater the $\left|\xi_{i}\right|$. The greater the impact of tolerance design variables $T_{i}$ on the machining cost of the closed-loop tolerance $T_{0}$, the smaller the $b_{i}$. All the absolute values of the transfer coefficients of the four component ring tolerances are 1 , but the corresponding $b_{i}$ are different. Therefore, based on the values of $\left|\xi_{i}\right|$ and $b_{i}$, $\left\{T_{3}, T_{9}, T_{10}, T_{12}\right\}$ was assigned to the quality game party $\mathrm{P} 1$, while $\left\{T_{1}, T_{2}, T_{4}, T_{7}, T_{8}, T_{11}\right\}$ was the strategy vector of the cost game party P2. Therefore, the strategies of each player in this case are the following:

The strategy vector of the quality game party P1: $s_{1}$ $=\left(s_{1,3}, s_{1,9}, s_{1,10}, s_{1,12}\right)=\left(T_{3}, T_{9}, T_{10}, T_{12}\right) \in S_{1} ; \quad$ the strategy vector of the cost game party P2: $s_{2}=\left(s_{2,1}, s_{2,2}, s_{2,4}, \quad s_{2,7}, s_{2,8}, s_{2,11}\right)=\left(T_{1}, T_{2}, T_{4}, T_{7}\right.$, $\left.T_{8}, T_{11}\right) \in S_{2}$.

Dimensionally normalize the objective function of assembly quality and manufacturing cost based on the utility and of each game party, and then $u_{1}$ and $u_{2}$ can be obtained as

$$
\begin{aligned}
& u_{1}(T)=\frac{T_{0}(T)}{\min T_{0}(T)}, \\
& u_{2}(T)=\frac{C(T)}{\min C(T)} .
\end{aligned}
$$

According to the utility calculation formula of the game party, the utility of each game party was calculated, and finally the game model of tolerance allocation was obtained, which is shown in Figure 6.

The game utility matrix of alliance $\{\mathrm{P} 1\}$ is shown in Figure 7. According to von Neumann's "Minimum Maximum Criterion," the characteristic function of the alliance $\{\mathrm{P} 1\}$ is $\nu(\{1\})=-0.0588$.

The game utility matrix of alliance $\{\mathrm{P} 2\}$ is shown in Figure 8. According to von Neumann's "Minimum Maximum Criterion," the characteristic function of the alliance $\{\mathrm{P} 2\}$ is $\nu(\{2\})=1.0152$.
The game utility matrix of alliance $\{\mathrm{P} 1, \mathrm{P} 2\}$ is shown in Figure 9. According to von Neumann's "Minimum Maximum Criterion," the characteristic function of the alliance $\{\mathrm{P} 1, \mathrm{P} 2\}$ is $\nu(\{1,2\})=-0.5882$.

$x=\left(x_{1}, x_{2}, \ldots, x_{n}\right)=\left(\varphi_{1}(\nu), \varphi_{2}(\nu), \ldots, \varphi_{n}(\nu)\right)$ is a distribution plan of the alliance game. For the Shapley vector $x_{i}$, each player will accept this resource allocation, because the utility of each player in cooperative game is not inferior to his own efforts, namely, $\varphi_{i}(\nu)<\nu(\{i\}), i=1,2$, and the specific calculation process is shown in (14) and (15). In this manuscript, whether it is a tolerance value or a cost value, the smaller the value, the better.

$$
\begin{aligned}
\nu(\{1\}) & =-0.0588, \\
\nu(\{2\}) & =1.0152, \\
\nu(\{1,2\}) & =\min \left\{u_{1}+u_{2}\right\} \\
x & =\left(x_{1}, x_{2}\right), \\
& =\left(\varphi_{1}(\nu), \varphi_{2}(\nu)\right) \\
& =(-0.8311,0.2429) \\
(-0.8311)+0.2429 & =-0.5882 .
\end{aligned}
$$

The Shapley value vector is $\Phi=\left(\varphi_{1}, \varphi_{2}\right)=(-0.8311$, 0.2429); we calculated all the two-norm of all the effective combination and the Shapley value and obtained the optimal utility combination is $\left(u_{1}^{*}, u_{2}^{*}\right)=(-0.8235,1.0045)$, the corresponding optimal strategy combination is $\left(s_{1-3}^{*}, s_{1-9}^{*}\right.$, $\left.s_{1-10}^{*}, s_{1-12}^{*}, s_{2-1}^{*}, s_{2-2}^{*}, s_{2-4}^{*}, s_{2-7}^{*}, s_{2-8}^{*}, s_{2-11}^{*}\right)=(0.1,0.1,0.025$, $0,-0.05,-0.05,0.025,0.05,0.1,0.05), \quad$ and $T_{0}=0.35$, $0.25<T_{0}<0.55$, where $T_{0}$ is within the design range of the flow gap. It meets the tolerance constraint requirements.

\subsection{Solution and Analysis of the Game Model of Steam Turbine} Tolerance Distribution. In this paper, the Shapley value method, the Nash equilibrium method, and the qualityconstrained cost optimization method were used to solve the optimization model of the steam turbine tolerance allocation. The solution results are shown in Table 1.

By comparing the solution results of the three methods in Table 1, the following conclusions could be obtained: the closed ring tolerance obtained by the Nash equilibrium method was $0.6750 \mathrm{~mm}$, which was beyond the design range of the closed ring tolerance of $0.25 \leq T_{b l} \leq 0.55$, and could not meet the design requirements. However, the solution results solved by the Shapley method and the traditional method of taking quality as constraint were, respectively, $0.3500 \mathrm{~mm}$ and $0.5250 \mathrm{~mm}$, which were all within the design range of the closed-loop tolerance. The cost obtained by the above three methods was almost the same, but the quality solutions obtained by them were significantly different. Although the closed-loop tolerances obtained by the Shapley value method and the qualityconstrained method were within the design range, the closed-loop tolerance obtained by the Shapley value method was $0.35 \mathrm{~mm}$, and the corresponding product quality is significantly better than that of the quality- 


\begin{tabular}{|c|c|c|c|c|c|c|c|}
\hline & \multirow{3}{*}{$\begin{array}{l}\text { Assembly product cost game } \\
\text { (P2) }-S_{2}\end{array}$} & \multicolumn{6}{|c|}{ Assembly product quality game $(\mathrm{P} 1)-S_{1}$} \\
\hline & & 1 & 2 & 3 & 4 & 5 & 81 \\
\hline & & $S_{1}=(0,0,-0.025,-0.1)$ & $S_{1}=(0,0,-0.025,-0.05)$ & $S_{1}=(0,0,-0.025,0)$ & $S_{1}==(0,0,0,-0.1)$ & $\ldots \ldots$ & $S_{1}==(0.2,0.1,0.025,0)$ \\
\hline 1 & $S_{2}=(-0.05,-0.05,0,-0.05,-0.1,-0.05)$ & $(1.0325,1.0)$ & $(1.0299,0.8824)$ & $(1.0273,0.7647)$ & $(1.0315,0.9412)$ & $\ldots \ldots$ & $(1.0173,-0.0588)$ \\
\hline 2 & $S_{2}=(-0.05,-0.05,0,-0.05,-0.1,0)$ & $(1.03,0.8824)$ & $(1.0273,0.7647)$ & $(1.0247,0.6471)$ & $(1.0289,0.8235)$ & $\ldots \ldots$ & $(1.0147,-0.1765)$ \\
\hline 3 & $S_{2}=(-0.05,-0.05,0,-0.05,-0.1,0.05)$ & $(1.0275,0.7647)$ & $(1.0248,0.6471)$ & $(1.0222,0.5294)$ & $(1.0264,0.7059)$ & $\ldots \ldots$ & $(1.0122,-0.2941)$ \\
\hline 4 & $S_{2}=(-0.05,-0.05,0,-0.05,0,-0.05)$ & $(1.0294,0.7647)$ & $(1.0268,0.6471)$ & $(1.0242,0.5294)$ & $(1.0284,0.7059)$ & $\ldots \ldots$ & $(1.0142,-0.2941)$ \\
\hline 5 & $S_{2}=(-0.05,-0.05,0,-0.05,0,0)$ & $(1.0269,0.6471)$ & $(1.0242,0.5294)$ & $(1.0216,0.4118)$ & $(1.0258,0.5882)$ & $\ldots \ldots$ & $(1.0116,-0.4118)$ \\
\hline 6 & $S_{2}=(-0.05,-0.05,0,-0.05,0,0.05)$ & $(1.0244,0.5294)$ & $(1.0217,0.4118)$ & $(1.0191,0.2941)$ & $(1.0233,0.4706)$ & $\ldots \ldots$ & $(1.0091,-0.5294)$ \\
\hline 7 & $S_{2}=(-0.05,-0.05,0,-0.05,0.1,-0.05)$ & $(1.0264,0.5294)$ & $(1.0238,0.4118)$ & $(1.0212,0.2941)$ & $(1.0254,0.4706)$ & ...... & $(1.0112,-0.5294)$ \\
\hline 8 & $S_{2}=(-0.05,-0.05,0,-0.05,0.1,0)$ & $(1.0239,0.4118)$ & $(1.0212,0.2941)$ & $(1.0186,0.1765)$ & $(1.0228,0.3529)$ & $\ldots \ldots$ & $(1.0086,-0.6471)$ \\
\hline 9 & $S_{2}=(-0.05,-0.05,0,-0.05,0.1,0.05)$ & $(1.0213,0.2941)$ & $(1.0187,0.1765)$ & $(1.0161,0.0588)$ & $(1.0203,0.2353)$ & $\ldots \ldots$ & $(1.0061,-0.7647)$ \\
\hline 10 & $S_{2}=(-0.05,-0.05,0,0,-0.1,-0.05)$ & $(1.031,0.8824)$ & $(1.0284,0.7647)$ & $(1.0258,0.6471)$ & $(1.03,0.8235)$ & $\ldots \ldots$ & $(1.0158,-0.1765)$ \\
\hline 11 & $S_{2}=(-0.05,-0.05,0,0,-0.1,0)$ & $(1.0284,0.7647)$ & $(1.0258,0.6471)$ & $(1.0232,0.5294)$ & $(1.0274,0.7059)$ & $\ldots \ldots$ & $(1.0132,-0.2941)$ \\
\hline 12 & $S_{2}=(-0.05,-0.05,0,0,-0.1,0.05)$ & $(1.0259,0.6471)$ & $(1.0233,0.5294)$ & $(1.0207,0.4118)$ & $(1.0249,0.5882)$ & $\cdots \cdots$ & $(1.0107,-0.4118)$ \\
\hline 13 & $S_{2}=(-0.05,-0.05,0,0,0,-0.05)$ & $(1.0279,0.6471)$ & $(1.0253,0.5294)$ & $(1.0227,0.4118)$ & $(1.0269,0.5882)$ & $\ldots \ldots$ & $(1.0127,-0.4118)$ \\
\hline 14 & $S_{2}=(-0.05,-0.05,0,0,0,0)$ & $(1.0253,0.5294)$ & $(1.0227,0.4118)$ & $(1.0201,0.2941)$ & $(1.0243,0.4706)$ & $\ldots \ldots$ & $(1.0101,-0.5294)$ \\
\hline 15 & $S_{2}=(-0.05,-0.05,0,0,0,0.05)$ & $(1.0228,0.4118)$ & $(1.0202,0.2941)$ & $(1.0176,0.1765)$ & $(1.0218,0.3529)$ & $\ldots \ldots$ & $(1.0076,-0.6471)$ \\
\hline$\cdots$ & $\ldots \ldots$ & $\cdots \cdots$ & $\cdots \cdots$ & $\cdots \cdots$ & $\cdots \cdots$ & $\cdots \cdots$ & $\ldots \ldots$ \\
\hline 729 & $S_{2}=(0.05,0.05,0.05,0.05,0.1,0.05)$ & $(1.0152,-0.5294)$ & $(1.0126,-0.6471)$ & $(1.01,-0.7647)$ & $(1.0142,-0.5882)$ & $\ldots \ldots$ & $(1.0,-1.5882)$ \\
\hline
\end{tabular}

Figure 6: The game model of tolerance allocation.

\begin{tabular}{|c|c|c|c|c|c|c|c|}
\hline & \multirow{3}{*}{$\begin{array}{l}\text { Assembly product cost requirements } \\
\text { (P2) }-S_{2}\end{array}$} & \multicolumn{6}{|c|}{ Assembly product quality requirements $(\mathrm{P} 1)-S_{1}$} \\
\hline & & 1 & 2 & 3 & 4 & 5 & 81 \\
\hline & & $S_{1}=(0,0,-0.025,-0.1)$ & $S_{1}=(0,0,-0.025,-0.05)$ & $S_{1}=(0,0,-0.025,0)$ & $S_{1}==(0,0,0,-0.1)$ & $\cdots \cdots$ & $S_{1}==(0.2,0.1,0.025,0)$ \\
\hline 1 & $S_{2}=(-0.05,-0.05,0,-0.05,-0.1,-0.05)$ & 1 & 0.8824 & 0.7647 & 0.9412 & a..... & -0.0588 \\
\hline 2 & $S_{2}=(-0.05,-0.05,0,-0.05,-0.1,0)$ & 0.8824 & 0.7647 & 0.6471 & 0.8235 & $\ldots \ldots$ & -0.1765 \\
\hline 3 & $S_{2}=(-0.05,-0.05,0,-0.05,-0.1,0.05)$ & 0.7647 & 0.6471 & 0.5294 & 0.7059 & ...... & -0.2941 \\
\hline 4 & $S_{2}=(-0.05,-0.05,0,-0.05,0,-0.05)$ & 0.7647 & 0.6471 & 0.5294 & 0.7059 & & -0.2941 \\
\hline 5 & $S_{2}=(-0.05,-0.05,0,-0.05,0,0)$ & 0.6471 & 0.5294 & 0.4118 & 0.5882 & $\ldots \ldots$ & -0.4118 \\
\hline 6 & $S_{2}=(-0.05,-0.05,0,-0.05,0,0.05)$ & 0.5294 & 0.4118 & 0.2941 & 0.4706 & & -0.5294 \\
\hline 7 & $S_{2}=(-0.05,-0.05,0,-0.05,0.1,-0.05)$ & 0.5294 & 0.4118 & 0.2941 & 0.4706 & a.... & -0.5294 \\
\hline 8 & $S_{2}=(-0.05,-0.05,0,-0.05,0.1,0)$ & 0.4118 & 0.2941 & 0.1765 & 0.3529 & $\ldots \ldots$ & -0.6471 \\
\hline 9 & $S_{2}=(-0.05,-0.05,0,-0.05,0.1,0.05)$ & 0.2941 & 0.1765 & 0.0588 & 0.2353 & a.... & -0.7647 \\
\hline 10 & $S_{2}=(-0.05,-0.05,0,0,-0.1,-0.05)$ & 0.8824 & 0.7647 & 0.6471 & 0.8235 & -..... & -0.1765 \\
\hline 11 & $S_{2}=(-0.05,-0.05,0,0,-0.1,0)$ & 0.7647 & 0.6471 & 0.5294 & 0.7059 & ...... & -0.2941 \\
\hline 12 & $S_{2}=(-0.05,-0.05,0,0,-0.1,0.05)$ & 0.6471 & 0.5294 & 0.4118 & 0.5882 & $\ldots \ldots$ & -0.4118 \\
\hline 13 & $S_{2}=(-0.05,-0.05,0,0,0,-0.05)$ & 0.6471 & 0.5294 & 0.4118 & 0.5882 & a... & -0.4118 \\
\hline 14 & $S_{2}=(-0.05,-0.05,0,0,0,0)$ & 0.5294 & 0.4118 & 0.2941 & 0.4706 & -..... & -0.5294 \\
\hline 15 & $S_{2}=(-0.05,-0.05,0,0,0,0.05)$ & 0.4118 & 0.2941 & 0.1765 & 0.3529 & $\ldots \ldots$ & -0.6471 \\
\hline$\cdots$ & $\ldots \ldots$ & $\ldots \ldots$ & & $\ldots \ldots$ & & & $\ldots \ldots$ \\
\hline 729 & $S_{2}=(0.05,0.05,0.05,0.05,0.1,0.05)$ & -0.5294 & -0.6471 & -0.7647 & -0.5882 & ...... & -1.5882 \\
\hline
\end{tabular}

FIGURE 7: The game utility matrix of alliance $\{\mathrm{P} 1\}$.

constrained method. For the flow gap of the steam turbine, when the cost is almost the same, and the tolerance value is within the design range, the smaller the tolerance value of the flow gap, the higher the working efficiency of the product, and the quality of the product is higher. Therefore, compared with the noncooperative game method and the traditional solution method of quality-constrained cost optimization, the Shapley value method in the cooperative game method that takes into account both quality and cost had the best solution effect. 


\begin{tabular}{|c|c|c|c|c|c|c|c|c|c|c|c|c|c|}
\hline & & \multicolumn{12}{|c|}{ Assembly product cost requirements $(\mathrm{P} 2)-S_{2}$} \\
\hline & & 1 & 2 & 3 & 4 & 5 & 6 & 7 & 8 & 9 & 10 & $\ldots \ldots$ & 729 \\
\hline \multirow{6}{*}{\multicolumn{2}{|c|}{$\begin{array}{l}\text { Assembly product quality } \\
\text { requirements }(\mathrm{P} 1)-S_{1}\end{array}$}} & -0.05 & -0.05 & -0.05 & -0.05 & -0.05 & -0.05 & -0.05 & -0.05 & -0.05 & -0.05 & $\ldots \ldots$ & 0.05 \\
\hline & & -0.05 & -0.05 & -0.05 & -0.05 & -0.05 & -0.05 & -0.05 & -0.05 & -0.05 & -0.05 & $\ldots \ldots$ & 0.05 \\
\hline & & 0 & 0 & 0 & 0 & 0 & 0 & 0 & 0 & 0 & 0 & $\ldots \ldots$ & 0.05 \\
\hline & & -0.05 & -0.05 & -0.05 & -0.05 & -0.05 & -0.05 & -0.05 & -0.05 & -0.05 & 0 & $\ldots \ldots$ & 0.05 \\
\hline & & -0.1 & -0.1 & -0.1 & 0 & 0 & 0 & 0.1 & 0.1 & 0.1 & -0.1 & $\ldots \ldots$ & 0.1 \\
\hline & & -0.05 & 0 & 0.05 & -0.05 & 0 & 0.05 & -0.05 & 0 & 0.05 & -0.05 & $\ldots \ldots$ & 0.05 \\
\hline 1 & $S_{1}=(0,0,-0.025,-0.1)$ & 1.0325 & 1.03 & 1.0275 & 1.0294 & 1.0269 & 1.0244 & 1.0264 & 1.0239 & 1.0213 & 1.031 & $\ldots \ldots$ & 1.0152 \\
\hline 2 & $S_{1}=(0,0,-0.025,-0.05)$ & 1.0299 & 1.0273 & 1.0248 & 1.0268 & 1.0242 & 1.0217 & 1.0238 & 1.0212 & 1.0187 & 1.0284 & ...... & 1.0126 \\
\hline 3 & $S_{1}=(0,0,-0.025,0)$ & 1.0273 & 1.0247 & 1.0222 & 1.0242 & 1.0216 & 1.0191 & 1.0212 & 1.0186 & 1.0161 & 1.0258 & $\ldots \ldots$ & 1.01 \\
\hline 4 & $S_{1}==(0,0,0,-0.1)$ & 1.0315 & 1.0289 & 1.0264 & 1.0284 & 1.0258 & 1.0233 & 1.0254 & 1.0228 & 1.0203 & 1.03 & $\ldots \ldots$ & 1.0142 \\
\hline 5 & $S_{1}==(0,0,0,-0.05)$ & 1.0289 & 1.0263 & 1.0238 & 1.0258 & 1.0232 & 1.0207 & 1.0228 & 1.0202 & 1.0177 & 1.0273 & $\ldots \ldots$ & 1.0116 \\
\hline$\cdots$ & $\ldots \ldots$ & $\ldots \ldots$ & $\ldots \ldots$ & $\ldots \ldots$ & $\ldots \ldots$ & $\ldots \ldots$ & $\ldots \ldots$ & $\ldots \ldots$ & $\ldots \ldots$ & $\ldots \ldots$ & $\ldots \ldots$ & $\ldots \ldots$ & $\ldots \ldots$ \\
\hline 81 & $S_{1}==(0.2,0.1,0.025,0)$ & 1.0173 & 1.0147 & 1.0122 & 1.0142 & 1.0116 & 1.0091 & 1.0112 & 1.0086 & 1.0061 & 1.0158 & $\ldots \ldots$ & 1 \\
\hline
\end{tabular}

FIGURE 8: The game utility matrix of alliance $\{\mathrm{P} 2\}$.

\begin{tabular}{|c|c|c|c|c|c|c|c|}
\hline \multirow{3}{*}{\multicolumn{2}{|c|}{$\begin{array}{l}\text { Assembly product cost requirements } \\
\qquad \text { (P2) }-S_{2}\end{array}$}} & \multicolumn{6}{|c|}{ Assembly product quality requirements $(\mathrm{Pl})-S_{1}$} \\
\hline & & 1 & 2 & 3 & 4 & 5 & 81 \\
\hline & & $S_{1}=(0,0,-0.025,-0.1)$ & $S_{1}=(0,0,-0.025,-0.05)$ & $S_{1}=(0,0,-0.025,0)$ & $S_{1}==(0,0,0,-0.1)$ & & $S_{1}==(0.2,0.1,0.025,0)$ \\
\hline 1 & $S_{2}=(-0.05,-0.05,0,-0.05,-0.1,-0.05)$ & 2.0325 & 1.9123 & 1.792 & 1.9727 & & 0.9585 \\
\hline 2 & $S_{2}=(-0.05,-0.05,0,-0.05,-0.1,0)$ & 1.9123 & 1.792 & 1.6718 & 1.8525 & & 0.8383 \\
\hline 3 & $S_{2}=(-0.05,-0.05,0,-0.05,-0.1,0.05)$ & 1.7922 & 1.6719 & 1.5516 & 1.7323 & $\ldots \ldots$ & 0.7181 \\
\hline 4 & $S_{2}=(-0.05,-0.05,0,-0.05,0,-0.05)$ & 1.7941 & 1.6739 & 1.5536 & 1.7343 & & 0.7201 \\
\hline 5 & $S_{2}=(-0.05,-0.05,0,-0.05,0,0)$ & 1.6739 & 1.5536 & 1.4334 & 1.6141 & & 0.5999 \\
\hline 6 & $S_{2}=(-0.05,-0.05,0,-0.05,0,0.05)$ & 1.5538 & 1.4335 & 1.3132 & 1.4939 & $\ldots \ldots$ & 0.4797 \\
\hline 7 & $S_{2}=(-0.05,-0.05,0,-0.05,0.1,-0.05)$ & 1.5558 & 1.4356 & 1.3153 & 1.496 & & 0.4818 \\
\hline 8 & $S_{2}=(-0.05,-0.05,0,-0.05,0.1,0)$ & 1.4356 & 1.3153 & 1.1951 & 1.3758 & & 0.3616 \\
\hline 9 & $S_{2}=(-0.05,-0.05,0,-0.05,0.1,0.05)$ & 1.3155 & 1.1952 & 1.0749 & 1.2556 & $\ldots \ldots$ & 0.2414 \\
\hline 10 & $S_{2}=(-0.05,-0.05,0,0,-0.1,-0.05)$ & 1.9134 & 1.7931 & 1.6728 & 1.8535 & & 0.8393 \\
\hline 11 & $S_{2}=(-0.05,-0.05,0,0,-0.1,0)$ & 1.7931 & 1.6728 & 1.5526 & 1.7333 & $\ldots \ldots$ & 0.7191 \\
\hline 12 & $S_{2}=(-0.05,-0.05,0,0,-0.1,0.05)$ & 1.673 & 1.5527 & 1.4325 & 1.6131 & & 0.5989 \\
\hline 13 & $S_{2}=(-0.05,-0.05,0,0,0,-0.05)$ & 1.675 & 1.5547 & 1.4344 & 1.6151 & $\ldots \ldots$ & 0.6009 \\
\hline 14 & $S_{2}=(-0.05,-0.05,0,0,0,0)$ & 1.5547 & 1.4344 & 1.3142 & 1.4949 & $\ldots \ldots$ & 0.4807 \\
\hline 15 & $S_{2}=(-0.05,-0.05,0,0,0,0.05)$ & 1.4346 & 1.3143 & 1.1941 & 1.3747 & & 0.3605 \\
\hline$\ldots$ & ....... & ...... & & $\ldots \ldots$. & & & ...... \\
\hline 729 & $S_{2}=(0.05,0.05,0.05,0.05,0.1,0.05)$ & 0.4858 & 0.3655 & 0.2453 & 0.426 & ...... & -0.5882 \\
\hline
\end{tabular}

FIgUre 9: The game utility matrix of alliance $\{\mathrm{P} 1, \mathrm{P} 2\}$.

TABLE 1: The solution and comparative analysis of the optimization model of steam turbine tolerance distribution.

\begin{tabular}{lcccccccccccccccccc}
\hline & \multicolumn{1}{c}{ Tolerance design variables $\begin{array}{c}\text { tolerances assigned to each component } \\
\text { ring) }\end{array}$} & \multicolumn{1}{c}{$\begin{array}{c}\text { Utility } \\
\text { Optimization } \\
\text { objectives }\end{array}$} \\
& $S_{1-3}^{*}$ & $S_{1-9}^{*}$ & $S_{1-10}^{*}$ & $S_{1-12}^{*}$ & $S_{2-1}^{*}$ & $S_{2-2}^{*}$ & $S_{2-4}^{*}$ & $S_{2-7}^{*}$ & $S_{2-8}^{*}$ & $S_{2-11}^{*}$ & $u_{1}$ & $u_{2}$ & $T_{0}(\mathrm{~mm})$ & $C$ \\
\hline Shapley value method & 0.1 & 0.1 & 0.025 & 0 & -0.05 & -0.05 & 0.025 & 0.05 & 0.1 & 0.05 & -0.8235 & 1.0045 & 0.3500 & 9.8668 \\
Nash equilibrium method & 0.2 & 0.1 & 0.025 & 0 & 0.05 & 0.05 & 0.05 & 0.05 & 0.1 & 0.05 & -1.5882 & 1.0000 & 0.6750 & 9.8226 \\
Quality-constrained method & 0.2 & 0.1 & 0.025 & 0 & -0.05 & 0 & 0.05 & 0.05 & 0.1 & 0.05 & -1.2353 & 1.0015 & 0.5250 & 9.8373 \\
\hline
\end{tabular}

\section{Conclusions}

(1) Aiming at the multiobjective optimization problem with contradictions and conflicts of the tolerance allocation of complex products, we took advantage of the features of coordinating and balancing contradictions and conflicts of cooperative game theory.
The quality requirements and cost requirements of assembly products were used as the game decision party, and the fuzzy clustering method was used to group the design variables of tolerance allocation problem of the steam turbine to form the strategic space belonging to each game party. Taking the quality level and cost level of the assembly product as 
the optimization goals, we completed the calculation of the utility belonging to the two game parties and established a set of multiobjective optimization model of steam turbine tolerance allocation based on cooperative game theory.

(2) Taking the solution of the multiobjective optimization model of steam turbine tolerance allocation as an example, the Shapley value method in cooperative game theory, the Nash equilibrium method in noncooperative game theory, and the traditional single-objective optimization method with quality as the constraint and the cost as the optimization objective were used to solve the problem. Comparing the cost solution results of the three optimization methods, the product cost obtained by the three methods was almost the same. Comparing the quality solution results, the Nash equilibrium solution still could be further optimized, and the Shapley value method cooperated from the perspective of collective interests and obtained a better result than the Nash equilibrium method. Moreover, the quality solution of the Shapley value method, which could coordinate and balance the optimization goals, was also significantly better than the traditional singleobjective optimization method that took quality as the constraint and the lowest cost as the optimization goal. Therefore, the example of the multiobjective optimization of steam turbine tolerance allocation showed that the cooperative game method balanced and coordinated quality and cost and realized the comprehensive optimization for the two goals from the perspective of collective interests, overcame the disadvantages of the traditional single-objective optimization method, and obtained a better result than Nash equilibrium method.

\section{Data Availability}

No data were used to support this study.

\section{Additional Points}

Aiming at the optimization problem of multiobjective with contradictions and conflicts of the tolerance allocation of complex products, we established a set of multiobjective optimization models of tolerance allocation based on cooperative game theory. And, the cooperative game solving method was used to solve the above established game model, and we achieved a good solution effect.

\section{Conflicts of Interest}

The authors declare that they have no conflicts of interest.

\section{Acknowledgments}

The authors gratefully acknowledge the financial supports by the National Key Research and Development Program of China under Grant no. 2019YFB1703800.

\section{References}

[1] S. Jiang and P. Wang, "Tolerance design based on green manufacturing," Tool Technology, vol. 44, no. 11, pp. 58-62, 2010.

[2] W. Wu and Z. W. She, "Tolerance optimization allocation method based on manufacturing-quality loss cost," Journal of Chang'an University (Natural Science Edition), vol. 25, no. 3, pp. 89-93, 2005.

[3] H. M. Fa and G. Y. Sheng, "A tolerance optimization design method based on the lowest manufacturing cost," Journal of Huazhong University of Science and Technology (Natural Science Edition), no. 4, pp. 19-21, 2002.

[4] C. Zheng, S. Jin, X. Lai, and Y. Li, "Tolerance allocation optimization based on non-cooperative game," Chinese Journal of Mechanical Engineering, no. 10, pp. 165-171, 2009.

[5] N. Siddique and H. Adeli, "Nature inspired computing: an overview and some future directions," Cognitive Computation, vol. 7, no. 6, pp. 706-714, 2015.

[6] B. K. A. Ngoi and O. C. Teck, "A tolerancing optimisation method for product design," International Journal of Advanced Manufacturing Technology, vol. 13, no. 4, pp. 290-299, 1997.

[7] G. Zhang, "Simultaneous tolerancing for design and manufacturing," International Journal of Production Research, vol. 34, no. 12, pp. 3361-3382, 2007.

[8] P. K. K. Singh, "Important issues in tolerance design of mechanical assemblies. Part 2: tolerance synthesis," Proceedings of the Institution of Mechanical Engineers-Part B: Journal of Engineering Manufacture, vol. 223, no. 10, pp. 1249-1287, 2009.

[9] A. Ashiagbor and B. O. Nnaji, "Tolerance control and propagation for the product assembly modeler," International Journal of Production Research, vol. 36, no. 1, pp. 75-94, 1998.

[10] A. Shan, R. N. Roth, and R. J. Wilson, "Genetic algorithms in statistical tolerancing," Mathematical and Computer Modelling, vol. 38, no. 11-13, pp. 1427-1436, 2003.

[11] H. B. Qiu, Y. Y. Dong, Y. Wang, and L. Gao, "Tolerance optimization design based on physical programming methods and PSO algorithm," Advanced Materials Research, vol. 346, no. 7, pp. 584-592, 2011.

[12] H. Towsyfyan, "The comparison of imperialist competitive algorithm applied and genetic algorithm for machining allocation of clutch assembly," International Journal of Engineering, vol. 26, no. 1, pp. 1485-1494, 2013.

[13] L. D. S. Coelho, "Self-organizing migration algorithm applied to machining allocation of clutch assembly," Mathematics and Computers in Simulation, vol. 80, no. 2, pp. 427-435, 2009.

[14] L. Ramesh Kumar, K. P. Padmanaban, S. G. Kumar, and C. Balamurugan, "Design and optimization of concurrent tolerance in mechanical assemblies using bat algorithm," Journal of Mechanical Science and Technology, vol. 30, pp. 2601-2614, 2016.

[15] D. Vignesh Kumar, D. Ravindran, N. Lenin, and M. Siva Kumar, "Tolerance allocation of complex assembly with nominal dimension selection using Artificial Bee Colony algorithm," Proceedings of the Institution of Mechanical Engineers, Part C: Journal of Mechanical Engineering Science, vol. 233 , no. 1 , pp. $18-38,2018$.

[16] W. Zeng, Y. Rao, and P. Wang, "An effective strategy for improving the precision and computational efficiency of statistical tolerance optimization," International Journal of Advanced Manufacturing Technology, vol. 92, no. 5-8, pp. 1933-1944, 2017. 
[17] D. Shringi and K. Purohit, "Simultaneous optimization of tolerances for prismatic part assembly in different stack up conditions," Internationl Journal Mining. Metallurgy Mechanical Engineering, vol. 1, no. 2, pp. 183-186, 2013.

[18] Q. Zhu and T. Başar, "Game-theoretic approach to feedbackdriven multi-stage moving target defense," in Proceedings of the International Conference on Decision and Game Theory for Security, pp. 246-263, Fort Worth, TX, USA, November 2013.

[19] Z. Yan and M. Guizani, Game Theory for Wireless Communications and Networking, CRC Press, Boca Raton, FL, USA, 2010.

[20] Z. Cheng, Research on Game Model and Solution Method of Car Body Tolerance Design Based on "Quality-Cost" Equilibrium, Shanghai Jiaotong University, Shanghai, China, 2011. 